\title{
DIE HEILIGEN WÄLDER DER SLAWEN IN POMMERN IM FRÜHEN MITTELALTER
}

\author{
Andrzej Kuczkowski, Kamil Kajkowski
}

\begin{abstract}
Zusammenfassung: Der Aufsatz beschreibt einen gewissen Typus von frühmittelalterlichen slawischen heiligen Orten, nämlich die heiligen Heine in Pommern (Nord-Polen). Heilige Heine sind Orte von Versammlungen und Gerichthaltung. Diese Art religiöse Orte lassen nur wenige archäologische Funde nach. Möglicherweise standen dort Heiligtümer aus Holz. Die Autoren erläutern einige heilige Heine ausgehend von archäologischen, ethnographischen und schriftlichen Quellen.
\end{abstract}

Stichworte: heidnische Religion, heilige Heine, Pommern, Slawisch

Der Begriff der heidnischen Kultorte in den westslawischen Ländern ist in den Untersuchungen über das frühe Mittelalter in dieser Gegend eine der meist bestrittenen Diskussionsthemen (Moszyński 1998). Das hat einige Gründe. Einer davon ist die Tatsache, dass alle Untersuchungen der Kultorte des frühen Mittelalters auf den Schriften von Christen basieren. Deshalb sind einige Stellen der erforschten Unterlagen unterschiedlich interpretierbar und das hat zur Entstehung zahlreicher - oft auch sich gegenseitig ausschließender - Meinungen geführt. Unklarheit bringt auch die Tatsache, dass man keinen von diesen Orten auf Basis von archäologischen Materialien eindeutig identifizieren kann Bertemes, Biehl 2001). Das verhindert die archäologische Bestätigung der Überlieferungen. Das alles führt dazu, dass die Identifikation der westslawischen Kultorte viele Fragen offen lässt und nicht selten äusserst lebendige Diskussionen hervorruft. Dank schriftlichen Quellen wissen wir, dass die westlichen Slawen im frühen Mittelalter einige Arten von Naturerscheinungen verehrt haben, die die Landschaft irgendwie besonders geprägt haben. Man kann hier vor allem Berge, Wasserquellen und Wälder hervorheben. Die Chronisten betonten es gerne, dass die Heiden - im Gegenteil zu den Christen - mehr das Geschaffene als den Schöpfer verehrt haben (creaturam anteponere Creatori) (Rosik 2000: 240). Da uns nur sehr wenige Quellen über die heiligen Wälder Pommerns zur Verfügung stehen, sind wir gezwungen, von der ethnographischen Literatur und anderen mittelalterlichen Schriften Gebrauch zu machen. 
In diesem Artikel haben die Autoren sich das Ziel gesetzt, diesen Begriff anhand von zugänglichen Forschungsmaterialien vorzustellen.

Der Begriff der heiligen Wälder wurde bisher nicht besonders oft behandelt (Tyszkiewicz 1972, Słupecki 2000, Kajkowski 2005). Dafür gibt es einen gewissen Grund. Wenn man die vorhandenen mittelalterlichen Quellen durchsieht, wird es einem bald klar, dass es entweder gar keine oder sehr wenige archäologischen Materialien zum Thema Kultorte der Slawen gibt. Außerdem konnte ein Berg oder eine Wasserquelle, die ursprünglich Gegenstand der Verehrung war, entheiligt werden oder in einen fremden Besitz gehen, und ein Wald konnte ja auch einfach abgeholzt werden. Von den Schriften, die über das Fällen heiliger Bäume berichten, kann man folgern, dass solche Taten von Missionären ausgeübt wurden.

Pommern ist ein polnisches Gebiet, woher die meisten erhaltenen Überlieferungen und Beschreibungen der heidnischen Kultorte stammen. Dieses Material verdanken wir drei Autoren, die den Lebenslauf von Otton aus Bamberg beschrieben haben. Nämlich machte Otton aus Bamberg in den Jahren 1124 und 1128 zwei missionarische Reisen in dieses Gebiet (mehr Mielczarski

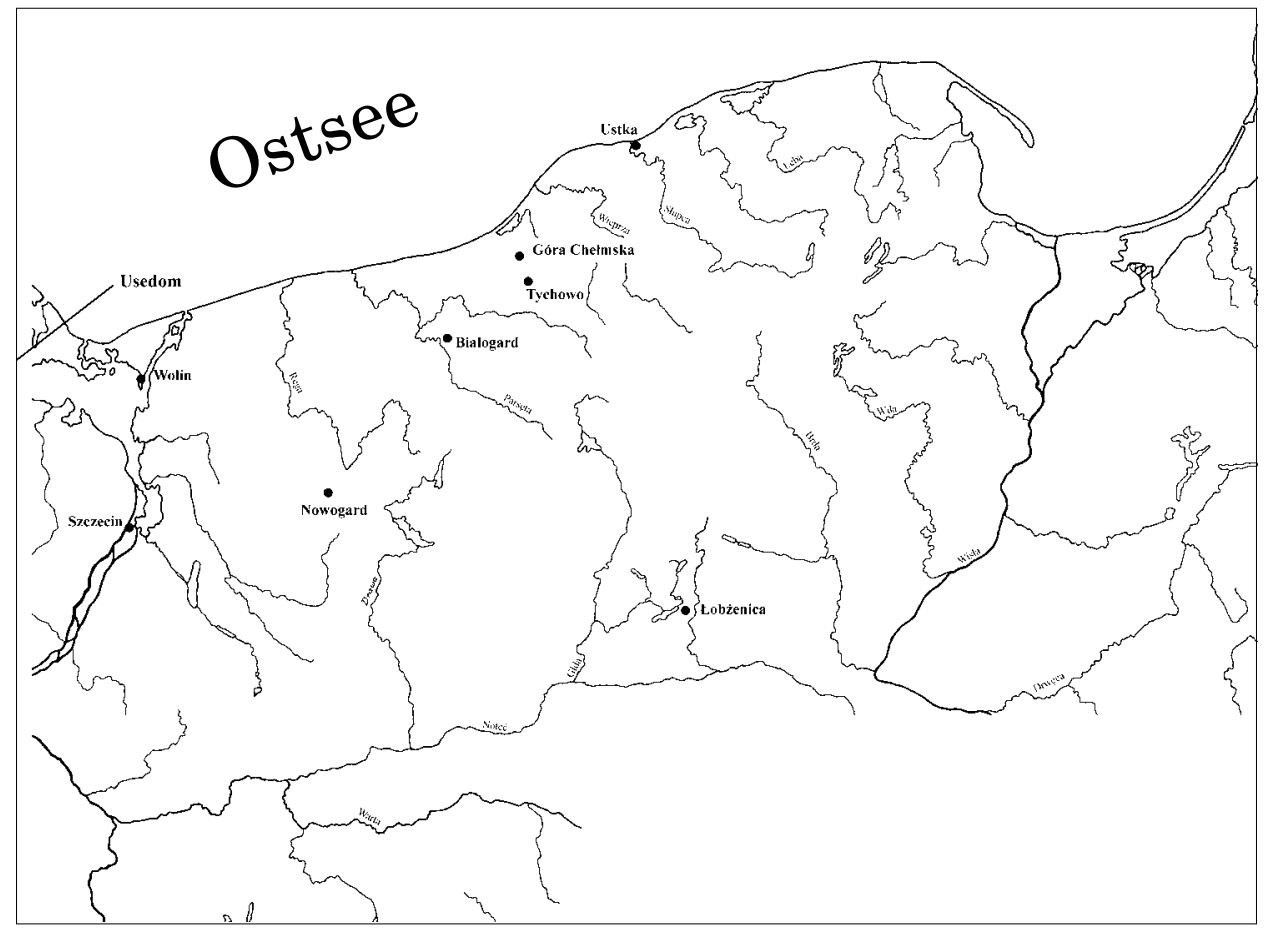

Bild 1. Landkarte mit allen im unseren Aufsatz erwähnten Orten. 
1992, Stępiński 2000, Zahajkiewicz 2000). Bei diesem Material findet man auch Abschnitte, die mit dem Thema dieses Artikels verbunden sind.

Als Herbord den Aufenthalt des Missionars in Stettin schildert, beschreibt er auch eine große Eiche, an deren Wurzeln eine Wasserquelle schlug, die Ort des Aufenthaltes von einem der Götter war (Herbordi... II: 32). Der zweite Autor, Ebbo, erwähnt bei der Beschreibung von Stettin auch einen Nussbaum, der nur deswegen nicht gefällt wurde, weil das Volk den heiligen Otton darum gebeten hat; als Dank mussten die Leute schwören, dass dieser Baum nicht mehr Ziel des heidnischen Kultes wird (Ebbonis 1872: III, 1). ${ }^{1}$ Den Zusammenhang von Nussbäumen mit dem heidnischen Glauben scheinen in den Gräbern gefundene Reste von Nüssen zu bestätigen (Niewęgłowski 1993).

Der letzte Abschnitt des Lebenslaufes von Otton liefert uns neue Details zur Erforschung der Bedeutung von Bäumen und Wäldern. Nämlich ist dort die Rede vom Verstecken einer goldenen Statue des Gottes Tryglaw, die ehemalig in Stettin aufbewahrt wurde, in einer Baumhöhle; der Name des Dorfes, wo der Baum stand, wird jedoch nicht genannt (Ebbonis 1872: II, 13; Stupecki 1995). Es ist klar, dass diese Statue nicht in einem gewöhnlichen Baum versteckt werden konnte.

Indirekt kann mit dem Begriff der magisch-religiösen Bedeutung der Bäume noch der folgende Text verbunden sein. Ein Mönch aus Prüfening schreibt über ein Attentat auf einen Missionar in Wolin: es soll sich jemand aus einer Gruppe von Menschen mit einem frisch abgebrochenen Baum auf ihn gestürzt haben und ihn so heftig damit geschlagen haben, dass der Missionar längere Zeit ohnmächtig war (Monachi Prieflingensis 1872: II, 6). Das Angreifen der Missionare von den Heiden mit solcher Art von Bewaffnung war keine Seltenheit. Auch die Preußen überfielen den heiligen Adelbert mit Schlägern aus Holz. Es ist möglich, dass dieses Holz von heiligen Bäumen stammte. Es gelte dann die Regel, dass man ein fremdes Heiligtum nur mit einem anderen, vergleichbaren vernichten kann (Cetwiński \& Derwich 1989: 38-39). Laut einigen Forschern konnten aus feierlich abgeschnittenen Zweigen oder Ästen Insignien säkularer Macht in Form von Stöcken oder Schlägern gemacht werden (Cetwiński \& Derwich 1989: 47). Bis zu dem heutigen Tag ist jedoch noch kein Argument zur Bestätigung dieser Hypothese beigefügt worden.

Wir wissen nicht, ob die Wälder Ort der Verehrung von einem der Götter (bzw. einer übernatürlichen Gestalt) ${ }^{2}$ waren oder ob es eine Gruppe von heiligen Orten mit verschiedenen Funktionen gewesen sind. Nur anhand von Vergleichen kann man folgern, dass die Eiche besonders mit dem slawischen Gott der Blitze und des Donners, Perun, verbunden war. Dies stammt aus der indoeuropäischen Tradition, in der der Gott der Blitze mit der Eiche verbunden wird (Tyszkiewicz 2003: 165), was auch von verschiedenen Autoren bestätigt 
worden ist (Kowalik 2004: 152, Marczewska 2001: 85-86). Dieser Baum wurde meistens gesehen als Heiligtum, Ort der Offenbarung, Abbildung des Weltalls, Symbol des Lebens, Zentrum der Welt, er symbolisierte aber auch das Wiederaufleben der Natur. Eigentlich begegnet man in der Geschichte jeder Religion - egal ob in historischen Quellen oder in der Kunst - solchen Bäumen. In vielen Kulturen sind sie neben Bergen und Inseln eines der wichtigsten kosmogonischen Elemente; axis mundi stärken die Stabilität der Welt, indem sie gleichzeitig den Baum des Lebens darstellen. Ein solcher Baum war nach Peter Duisburg die Eiche in dem preußischem Romowe (Bialuński 2002: 579-580) oder auch die skandinavische Esche Yggdrasil (Maciszewski 2004).

Nur im Falle des Prowe Waldes haben wir direkte Information über eine vermutlich übernatürliche Gestalt, die in einem bewaldeten Ort verehrt wurde. Wieso nur vermutlich? In der überlieferten Texten gibt es keine Information über den Prowe Kult. Man sagt nur, dass der Wald dieser Gestalt gewidmet war. Man kann sich hier auf die antiken Quellen berufen. Interessante Daten liefern uns die Schriften von Tacitus, in denen germanische Religionen beschrieben werden. Er schreibt, dass das Volk die heiligen Orte nicht mit Mauern und großen Figuren einzäunt oder schmückt. Es soll die Wälder verehrt haben und den Bäumen Namen gegeben haben (Dudley 1846: 65).

Wir wissen von noch einem Wald, den auch die Slawen für heilig gehalten haben. Die Sage von Knytling berichtet über den Überfall von Dänen auf Rügen in 1165. Der Text besagt, dass die Dänen sich zuerst auf die Insel Strela richteten, um dort den heiligen Buchenwald zu vernichten (Osięglowski 1971: 195, Slupecki 2006: 66). Aus diesem Namen, der auf einen Baum hinweist, wird jedoch nicht klar, welche Gestalt dort genau verehrt wurde.

Bisher beschäftigten wir uns hauptsächlich mit schriftlichen Materialien, nun wenden wir uns zu archäologischen, ethnographischen und mit Namen verbundenen Quellen.

In einer von uns früher vorgeschlagenen geographischen Einteilung der heiligen Berge in Polen, die auf einer allgemeineren Klassifikation der sakralen Gebiete basiert, gibt es den sogenannten "offenen" Typ - das sind Orte, bei denen man von keinem archäologisch feststellbaren Abgegrenztsein sprechen kann (Kuczkowski 2007). Dieser Sachverhalt kann mehrere Gründe haben: wenige Ausgrabergebnisse, völlige Zerstörung solcher Objekte u.s.w. In manchen Fällen kann man aber solche Spuren offensichtlich nur deshalb nicht finden, weil diese Orte tatsächlich auf keinerlei Weise abgegrenzt waren. Aus dieser Hinsicht ist die Geschichte des Berges Chelmska in der Nähe von Koszalin interessant (mehr: Kuczkowski 2004, 2005). Dieser Berg war im frühen Mittelalter den lokalen Bewohnern schwer zugänglich. Am Fuße des Berges befanden sich Sümpfe und Wälder, die ihn von der restlichen Landschaft klar abge- 
grenzt haben (Kuczkowski, zu druckt a, b, c,). Logischerweise sollte dieser Sachverhalt sich auch in den Überlieferungen des Volkes widerspiegeln. In der Tat aber wird das ganze damalige Geschehen eben auf den Hügeln oder am Fuße des Berges dargestellt (Kuczkowski, zu druckt a).

In Legenden der Völker trifft man oft auf das Motiv, dass ein Held durch einen Wald zu gehen plant. Da werden alle Dimensionen menschlicher Existenz aufgehoben, auch die Zeit (Rzepnikowska 2002: 613). So ist es notwendig, zuerst mehrere Rituale durchzumachen, um sich zeitlich aus der Gegenwart abzuschalten (profanum) und in den heiligen Raum zu gelangen. Der Waldweg zum heiligen Ort scheint für solche religiösen Tätigkeiten gerade der richtige Platz.

Man lenke die Aufmerksamkeit auf die Herkunft des Wortes "Gaj" - Wald in den slawischen Sprachen. Es bedeutet "eingrenzen". Also handelt es sich hier um eine von der Außenwelt abgegrenzte Umgebung. Dieses Wort stammt aus dem urindoeuropäischen Wortstamm *g*eiH; *g*oiH; *g*iH, was 'heilen', 'wiederaufleben' bedeutet (Duma 2002: 30). ${ }^{3}$ Es ging dabei nicht um eine Grenze, die physisch etwas absperren sollte. Es ging um eine symbolische Bezeichnung einer Grenze, die zwei gegensätzliche Begriffe voneinander trennt (sacrum und profanum) (Duma 2002). Sogar bei der Beschreibung eines gewissen Tempels (Radogoszcz) betont Thietmar aus Merseburg, dass er sich in der Mitte eines von Menschen unberührten Waldes befand, den man auch als heilig bezeichnete (Thietmar 2002: VI, 23-25).

Diese Grenzen hatten einen symbolischen Charakter und waren keine festen Konstruktionen. Im Falle des Waldgottes Prowe in Wagria bildete zum Beispiel ein Holzzaun diese Grenze (Helmolda 1974: I, 84). Von der Beschreibung wissen wir, dass der mit diesem Zaun abgegrenzte Raum eine Stelle war, wo sich die lokalen Menschen versammeln konnten. Wir wissen nicht, ob diese Stelle extra durchs Fällen von Bäumen geschaffen wurde oder handelte es sich einfach um eine natürliche Waldlichtung. Wahrscheinlicher ist die zweite Version, und zwar deswegen, weil eine Waldlichtung als Gegenteil zum dunklen Wald verstanden werden konnte (hell-dunkel, bekannt-unbekannt, sichtbar-unsichtbar u.s.w). Eine Waldlichtung ist ein Phänomen, das wissenschaftlich schwer zu erklären ist. Eine plötzliche leere Stelle im dichten Wald führt den Gedanken leicht auf übernatürliche Kräfte (Grad 2000: 23-24). Einen noch weniger spektakulären Zaun verwendete man im preußischen Wald Romowe; laut dem Chronisten bestand dieser aus weißen Stoffteilen und in die Erde eingeschlagenen Holzbalken (Preussische Chronik 1876: 78).

Es scheint, dass solche in diesen wichtigen Stellen gebaute Zäune etwas zu wenig bekannt sind, worauf auch die Schriften von Helmold hinweisen (Insignes portarum frontes $).{ }^{4}$ Vielleicht stammt von hier auch der Brauch, beim Bauen 
von Zäunen geschnitzte Elemente zu benutzen - bekannt von heidnischen Tempeln der an der Ostsee ansässigen Slawen (Schuldt 1976), aus Breslau (Moździoch 2000)5 oder aus ostslawischen Gebieten (Sedov 1981: 73). Es ist erwähnenswert, dass das Einzäunen von bedeutsamen Bäumen noch bis zum heutigen Tag praktiziert wird.

Im Gegenteil zu Gebieten, die von baltischen Völkern bewohnt waren (Jonuks 2007: 14), hat die Herkunft der Namen im Falle der slawischen Regionen (vor allem Pommern) eine ganz geringe Bedeutung. Auf dem letztgemeinten Gebiet wurden Ortsnamen mehrmals verändert - zuerst wurden die traditionellen Namen germanisiert, später, nach dem Anschließen Pommerns zu Polen nach dem zweiten Weltkrieg wurden sie aber wieder slawisch. Dabei wurde mit Namen häufig relativ frei umgegangen, ohne ihren historischen Hintergrund zu berücksichtigen. Als Folge konnten Teile der Ortsnamen, die auf die Stellen von heiligen Wäldern hätten hinweisen können, einfach verschwinden, oder wurden sie Orten gegeben, die ursprünglich mit heiligen Wäldern nichts zu tun hatten. Als Beispiel dafür kann man die Untersuchungen aus der Gegend um Nowogard in West-Pommern nennen. In dieser Umgebung fand man 816 Ortsnamen, die irgendwie auf Bäume hinwiesen - darunter $66 \mathrm{Na}$ men slawischer, 279 deutscher und 199 gemischter Abstammung aus den Jahren 1945-1948 und 272 gegenwärtige Namen (Afeltowicz 2004: 68). Eine so große Menge von Namen, die mit Bäumen verbunden sind, weist darauf hin, dass diese eine wichtige Rolle in der Kultur gespielt haben. Bis zu der heutigen Zeit verfügen wir aber noch über keine Materialien, die es uns ermöglichen würden, irgendeine von diesen Namensgruppen mit dem Bereich des Volksglaubens zu verbinden.

Indirekte Angaben haben wir aus preußischen und finnischen Gebieten. Man kann sich hier auf die Herkunft des Namens vom Wald Romowe berufen, der laut schriftlichen Quellen der wichtigste religiöse Ort des Landes war (Preussische Chronik 1876: 78). Nach Antoni Mierzyński stammt der Name aus dem Adjektiv ramus, romus - 'leise, leicht, ruhig'. Wenn man noch die Endung -ovja hinzusetzt, bekommt man das Wort Romovja, Romowe, was eine ruhige Stelle bedeutet, also "Ort der Beruhigung der Götter" (Mierzyński 1896: 24). In der finnischen Sprache bedeutet romeikko 'Reisig', rome 'Windbruch', romentola 'großer, alter Baum' (Haavio 1979, 62). Also weist die Bedeutung des Namens auf einen Ort hin, der nicht von Hand des Menschen berührt wurde, auf einen Ort, wo nicht einmal Windbruch weggeräumt wurde (Bialuński 2002). Wenn man dieses mit Angaben der schriftlichen Quellen vergleicht, legt die Vermutung nahe, dass man Ähnliches auch über die slawischen Wälder behaupten kann. Außerdem sind die sogenannten "natürlichen Tempel" - also 
von der Hand des Menschen unberührte Tempel - die ältesten Tempel überhaupt (Leeuv 1978: 439).

Von den Grundsätzen von Mircea Eliade ausgehend kann man annehmen, dass es niemals eine einzige separate heilige Erscheinung gegeben hat; man verknüpfte mit den heiligen Orten mehrere wundervolle Phänomene, die zusammengestellt in den Augen der Gläubigen eine Botschaft oder ein Symbol darstellten (Eliade 2000: 47). Also kann man vermuten, dass Bäume ein Teil vieler slawischer Tempel waren. Es ist auch nicht ausgeschlossen, dass einzelne Bäume oder Wälder, die damals beschrieben worden sind, ein Teil von einem ganzen Komplex von Kultobjekten gewesen sind. Die Quellen, die uns heute zur Verfügung stehen, erlauben es uns jedoch nicht, diese Vermutung zu beweisen.

Um die offenen Fragen zu beantworten und die Kultorte, Wälder und Bäume wieder aufzufinden, können wir annehmen, dass heilige Orte ihren Wert nicht verlieren, sondern nur an andere Religionen weitergegeben werden, sie gehen als Erbe weiter (Eliade 2000: 391). Im Mittelalter haben die christlichen Autoren die Verehrung von Bäumen und Wäldern oft als eine schwere Sünde bezeichnet. Besonders Cesar aus Arles hat solche Bräuche kritisiert und Wälder und Wasserquellen als Kirchen für abergläubige Menschen bezeichnet. Er unterstreicht, dass diese Orte wie Verstecke aussehen, und betont noch weiter, dass Gottestempel für alle zugänglich sein und im Zentrum des sozialen Lebens stehen sollten (Olszewski 2002: 25). Man hat auch das Pflanzen der Bäume um Kirchen, Kapellen, Kreuze oder Gräber als Erinnerung an die Verehrung heiliger Wälder angesehen, was tatsächlich nicht nur ästhetische Gründe hatte, sondern auch mit dem Urglauben zusammenhängen konnte (Blaszczyk 2000).

Es gibt Beweismaterial über mehrere heidnische Tempel in Pommern (Rogge 1927: 125-126). In den meisten Fällen ist die Rede von Tempeln, Inseln oder Opferfelsen. Man muss hier noch hinzufügen, dass die Bezeichnung "heidnisch" nicht immer eine religiöse Bedeutung zu haben braucht; in diesem Kontext dient sie eher als chronologische Feststellung. So bedeutet heidnisch hier allgemein 'alt', weil wir hier von den Zeiten vor der Einführung des Christentums sprechen. Außerdem wurde auf den Kaschuben auch der Teufel mit der Benennung - "pogan" (also Heide) bezeichnet (Bystroń 1980: 213), was zur Entstehung von Ortsnamen mit einem ähnlichen Adjektiv führte. Deshalb kann das Wort 'heidnisch' nur dann in der religiösen Bedeutung verstanden werden, wenn es zusammen mit einem Kultobjekt z.B. Tempel, Stein, Wald erscheint. Zum Beispiel Legenden über heidnische Tempel können eine Erinnerung an das tatsächliche Existieren irgendeines Tempels an dieser Stelle sein (Urbańczyk 1947: 62). Man muss aber hinzufügen, dass die Tradition allein 
noch kein ausreichendes Motiv ist, um irgendwo einen vorchristlichen Tempel zu identifizieren. Sie kann nur Anhaltspunkt zu weiteren Untersuchungen bestimmter Orte sein. Die Gesamterinnerung der Leute wurde am meisten von solchen Erlebnissen wie Kriege, Seuchen oder Völkerwanderungen geprägt (Samsonowicz 1997: 157). Wie man aus dem Lebenslauf des heiligen Otton aus Bamberg und anderer Missionaren folgern kann, waren die Aktionen der Vernichtung heidnischer Tempel ein bedeutsames Ereignis und ihre Beschreibungen wurden später noch lange mündlich weitergegeben.

Einer der interessantesten und bis heute noch unbeschriebenen Orte dieser Art ist der Klosterberg neben Łobżenica an der südlichen Grenze von Pommern. Die Tradition verknüpft zwei sich dort befindenden Objekte mit dem vorchristlichen Glauben - das sind eine Art Granit-Taufbecken, wahrscheinlich aus einem heidnischen Kultstein geschlagen, und ein kleiner Wald mit einem kleinen Hügel in der Mitte, dessen Funktion uns (noch) nicht bekannt ist (Skiba 1999). Dieser Ort sollte in der Zukunft einer Untersuchung durch Ausgrabungen unterzogen werden. Eine Holzkirche, die dort 1111 gegründet wurde - genau auf der Stelle, wo 1079 die Heilige Mutter Gottes gesehen wurde (Skiba 1999: 95) -, macht diese Umgebung für den Forscher noch interessanter. Außerdem ist das Datum dieser Offenbarung identisch mit dem des Todes von Krakau Bischof Stanisław aus Szczepanów. Dieser Sachverhalt deutet darauf hin, dass diese zwei Ereignisse auf kirchlich-politischer Ebene zu verknüpfen sind. Man sollte aber hier die Aufmerksamkeit auch auf die lange Zeitspanne zwischen dem Wunder (1079) und der Erbauung der erwähnten Kirche lenken (1111). In der Literatur wird betont, dass in den Chroniken von Gall Anonim bis 1108 keine Versuche erwähnt werden, das Christentum in dieser Region einzuführen (Powierski \& Śliwiński \& Bruski 1993: 44). Man kann nicht ausschließen, dass die Gründung dieser Kirche als Akt einer Missionaraktion in den Grenzgebieten Pommern verstanden werden sollte. Die Bestätigung dieser Reihenfolge würde einen großen Schritt in der Erforschung der Christentumseinführung in dieser Region bedeuten.

Einen solchen Verlauf der Ereignisse bestätigen einige Volksüberlieferungen, die auch in Preußen bekannt gewesen sind. Ähnlich wie in historischen Materialien widerspiegeln sich auch in ihnen Erinnerungen an Wälder, die als Wohnort übernatürlicher Gestalten angesehen wurden (besonders Portimpus) (Lapo 2007).

Eine indirekte Methode zum Auffinden von Wäldern, die auf irgendeine Weise verehrt worden sind, ist das Forschen von alten Gräbern. Es ist nämlich ausgerechnet worden, dass diese in etwa 25 bis 40 Jahren komplett vernichtet würden, wenn sie sich auf einem Gebiet befanden, welches zu landwirtschaftlichen Zwecken benutzt wird (Buko 2004: 77). Da sie aber noch bis zu der heuti- 

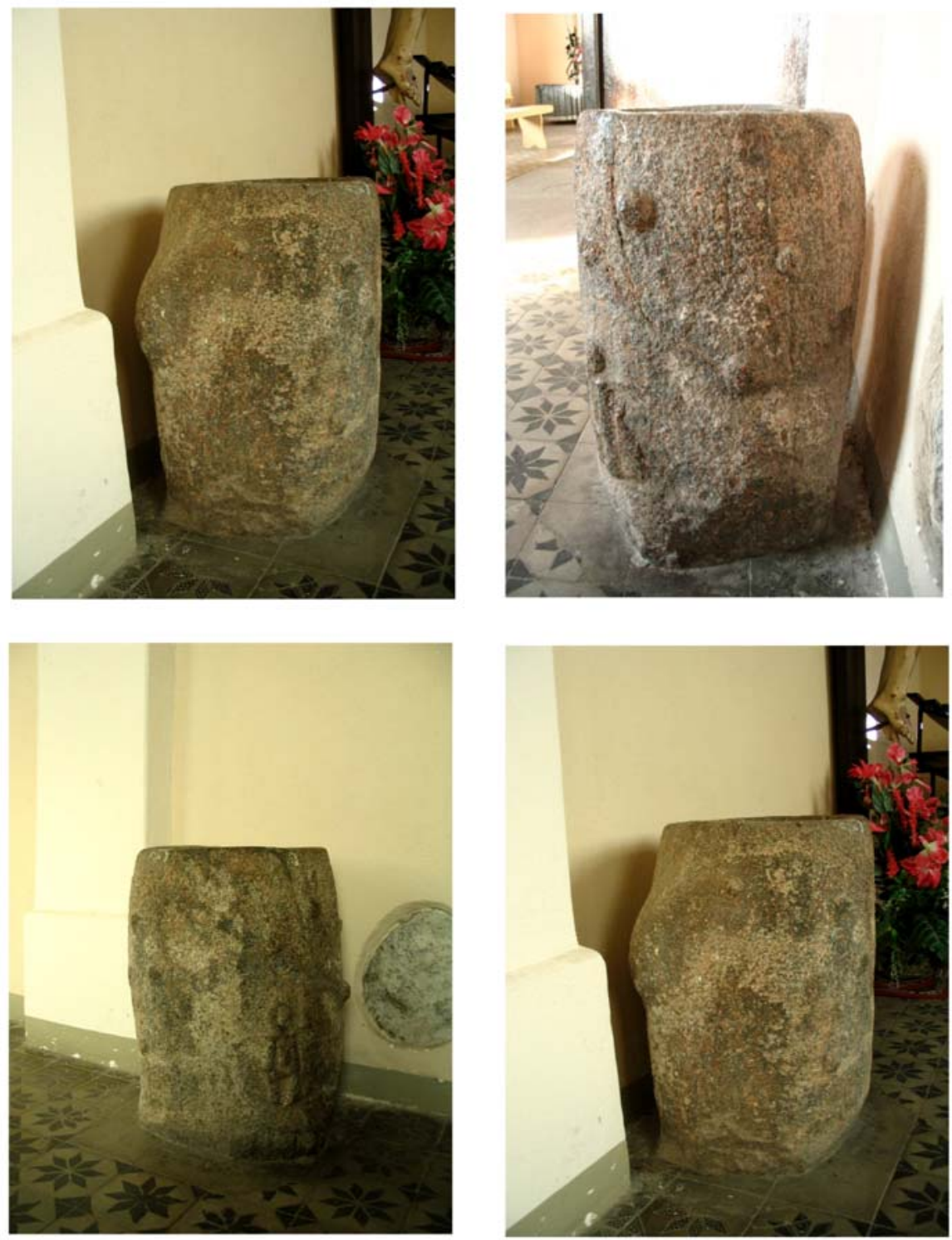

Bild 2. Lobżenica - Górka Klasztorna. Granit-Taufbecken, wahrscheinlich aus einem heidnischen Kultstein geschlagen (Photo R. Nowicki, Februar 2007).

gen Zeit existieren, kann man davon ausgehen, dass sie sich wenigstens teilweise außerhalb solcher Gebiete befanden, einige auch im Wald. Solche Gräber kann man als "Zeichen oder Andenken der Vergangenheit" bezeichnen (Ricouer 2007: 538). Es ist eines der dauerhaftesten Möglichkeiten, den Ort der Beerdigung eines Toten zu markieren. Deswegen haben diese Stellen in 
der damaligen Kultur zu den wichtigsten Kultobjekten gezählt (por. Noort 1993, Lutovský 1996, Holtorf 1997, Semple 1998). Wenn man bedenkt, dass auch die Slawen im frühen Mittelalter manchmal solche Gräber benutzten, mussten sie auch von dem Zweck solcher Objekte noch älterer Abstammung bewusst sein. Es ist nicht ausgeschlossen, dass die früheren Hünengräber Friedhöfe im frühen Mittelalter Ort sozialer Tätigkeiten waren. Es sind Fundorte in Pommern bekannt, wo Materialien aus diesem Zeitalter gefunden worden sind, die das bezeugen. ${ }^{6}$ Aber es gibt noch keine Untersuchungen, die eine solche Funktion der mittelalterlichen Friedhöfe bestätigen würden.

Dank schriftlichen Quellen wissen wir, dass Bäume im älteren Glauben mit der Welt der Toten verbunden wurden. Das führt den Gedanken auf Ruhestätten "in silvis et in campis" (Bylina 1996: 10), die als Ort von feindlichen übernatürlichen Kräften angesehen wurden. Die Anwesenheit von solchen Kräften war eben Grenzgebieten charakteristisch. Oft waren sie Versteck für Verbrecher und Aufenthaltsort für verschiedene Dämonen (por. Blaszczyk 2000). In Ustka kannte man den Brauch, Bäume vom Tod ihres Besitzers zu benachrichtigen (Bonowska 1999: 68). Im Grenzgebiet Pommerns, auf der Insel Usedom, befindet sich eine frühmittelalterliche Siedlung. Ein Teil von der Siedlung ist ein Friedhof aus dem 10.-12. Jahrhundert. Bemerkenswert ist die Benennung dieses Gebietes - "Am Hain" (Biermann 2006).

Unter den Beschreibungen der missionarischen Tätigkeiten des heiligen Otton findet man auch die Bemerkung, dass es verboten wurde, auf Gräber Zweige zu legen. Die Bedeutung dieses Brauches ist nicht ganz klar, aber auch hier erscheint wieder die Verbindung zwischen Bäumen und der Welt der Toten. Es ist ebenso unbekannt, ob solches Handeln auch mit einem späteren Brauch verbunden war, der darin bestand, auf der Stelle eines Todesunfalls ganze Haufen von Zweigen hinzulegen, um an den Ort des Todes zu gedenken (Bonowska 2002).

Zum Schluss möchten wir uns noch einmal auf die ethnographischen Quellen berufen. Die Verbindung zwischen dieser Art von Überlieferungen, die meistens im 19. Jahrhundert aufgezeichnet wurden, und dem traditionellen Glauben der polnischen Regionen ist auch nicht ganz klar. Die Archäologen haben hier häufig Spuren aus den heidnischen Bräuchen sehen wollen. Ohne in diese Diskussion gründlicher einzugehen, möchten wir hier nur auf das Darstellen von Bäumen in der Volkskultur aufmerksam machen. Wahrscheinlich ist ein Teil von diesen Überlieferungen wirklich ein Überbleibsel vom damaligen Glauben. Aber zu dem heutigen Stand der Untersuchungen kann man darüber nichts genaueres sagen.

Die Ethnographen des 19. Jahrhunderts betonten oft das außergewöhnliche Verhältnis der Dorfbewohner zu den Bäumen. Einerseits zeigten die Bau- 
Bild 3. Eine vorchristliche Kultstätte (Gemälde von M. Wawrzeniecki, 19. Jh. (nach Wrońska 1986: 67, Fig. 14).

ern den Bäumen gegenüber eine weitgehende Respektlosigkeit, indem sie viele von ihnen abgeholzten. Andererseits aber waren Bäume, die sich in der Nähe von Kirchen oder Friedhöfen befanden, sehr geschätzt und gepflegt. Man glaubte, dass auch eine geringe Verletzung solcher schwere gesundheitliche Folgen (Kaczmarek 2006: 510) oder sogar den Tod in der Gemeinde (Bystroń 1980: 175) mitbringen würde.

Es scheint, dass die Bäume sowohl im heidnischen Glauben, als

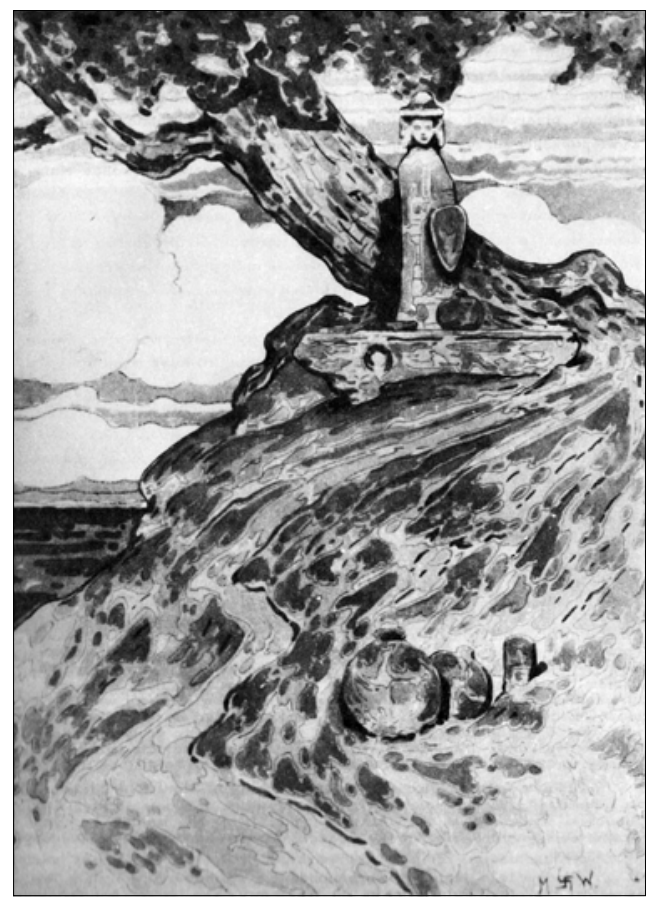
auch in Volksüberlieferungen der Aufenthaltsort von übernatürlichen Kräften waren. Laut dem Urglauben sollen sie Orte von Offenbarung der Götter oder anderer übernatürlicher Wesen gewesen sein (Eliade 1988: 163), in der Volkstradition waren sie Ort des Aufenthalts von Seelen oder später von Mutter Gottes oder anderen Heiligen, manchmal aber auch von Dämonen und dem Teufel ${ }^{8}$ selbst (Moszyński 1932: 519, Blaszczyk 2000: 49). Der Wald soll unter anderem auch ein Ort gewesen sein, wo sich die Hexen versammelten, um dort teuflische Bräuche auszuüben (Knoop 1895: 35). Besonderer Aufmerksamkeit erfreuten die Bäume, die schon von Tradition her Gegenstand der Sagen waren, oder - wie schon gesagt -, in der Nähe von Kirchen, Kreuzen oder Friedhöfen standen. Es gab auch Sagen über Wunderquellen. Verehrt wurden auch Bäume, die Wohn- oder Offenbarungsort von Heiligen waren, und solche, denen heilende Kräfte beigemessen wurden (oft verknüpfte man beide Phänomene mit einem Baum). Es gibt Vermutungen, dass der Brauch, den Weihnachtsbaum zu schmücken und um ihn zu laufen (Moszyński 1932: 527) ${ }^{9}$ heidnische Wurzeln hat. Der Brauch, den Bäumen zu drohen, dass sie abgeschnitten werden, wenn sie keine Früchte geben, kann ebenso eine magische Funktion gehabt haben (Moszyński 1932: 522). Ähnlich wie im vorchristlichen Glauben, war die Eiche in der späteren Volkstradition besonders beliebt, man hielt sie für einen guten und sogar heiligen Baum (Moszyński 1932: 527-528). Laut der Volksmedizin kann man sei- 
ne Blätter, Zweige und Früchte zu heilenden Zwecken anwenden. Allein den Blättern schrieb man abwehrmagische Kräfte zu. Noch bis vor kurzem gab es in Polen den Brauch, beim Bauen einer Strasse oder eines Hauses eine Eiche zu pflanzen. In Pommern bei den Kaschuben glaubte man, dass jede Eiche eine Seele hat und man den Baum deswegen nicht abschneiden darf. Zwischen dem 19. und 20. Jahrhundert hat man oft zu Geburten, Hochzeiten oder sogar Todesfällen eine Eiche gepflanzt (Łuka 1973: 39).

Aus dem obengenannten kann man schließen, dass nur die Teile des Waldes verehrt wurden, die den Menschen unheimlich schienen. Auch der in der Wende des 19. und 20. Jahrhunderts gelebte Dichter Stanisław Staszic schrieb über seinen Besuch in einen Hain bei Parczew in Ost-Polen, über welchen das Volk zahlreiche Legenden erzählte (Abramowicz 1987: 245-146).

Zusammenfassend kann man sagen, dass der frühmittelalterliche Hain ein heiliger Ort war, den man mit Hilfe von archäologischen Untersuchungen nicht eindeutig einordnen kann. Er war ein spezifischer Ort auf der damaligen Landschaft. Aus irgendeinem Grund wurde ein Teil des Waldes von dem Rest mit Zäunen oder Stoffen abgegrenzt. In solchen Stellen war das Eingreifen in die Natur Tabu. Man weiß nicht, ob die Slawen in den Wäldern übernatürliche Gestalten verehrten, ebenso weiß man nicht, ob der ganze Hain diese heilige Stelle war oder nur ein Teil davon. Wenig hilfreich sind für uns auch die Schlußfolgerungen, die wir auf Basis von Namen der Ortschaften oder Gebiete machen können. Nur solche schriftliche Quellen, die direkt einen heiligen Hein beschreiben, sind eine zuverlässige Quelle der Information. Leider ist keine von diesen Stellen bis heute mittels archäologischer Methoden bestätigt worden. Daher sind wir immer noch gezwungen, weitgehende Vermutungen zu schließen.

\section{ANMERKUNGEN}

${ }^{1}$ Man könnte hier noch andeuten, dass eine ähnliche Situation während einer Missionaraktion in Litauen stattfand. Als Hieronim aus Prag die Heiden über das Fällen von heiligen Wäldern überzeugen wollte, traf er auf einen starken Wiederstand von dort ansässigen Frauen, die diese für das Heim der Götter hielten (Frazer 1969: 129).

${ }^{2}$ Man hat die Herkunft der Namen einiger preußischen Gebiete geforscht und festgestellt, dass das Fragment "Kurko" häufig im Zusammenhang mit der Linde auftritt (Białuński 1993: 10).

${ }^{3}$ Der Baum hat gegenüber anderen Objekten den Vorteil, dass er lebt. Den Übergang vom lebendigen Baum zum Stein kann man symbolisch als progressive Entwicklung verstehen (Stein ist resistenter). Es kann aber auch als Unterstufung verstanden werden (als Sterben) (Pastoureau 2006: 93). 
${ }^{4}$ Helmolda 1974: I, 84.

${ }^{5}$ In diesem Kontext scheint die Theorie von Slawomir Moździoch (2000: 179) interessant. Er deutet an, dass man nach dem Baustil folgern könne, dass der Tempel aus Breslau unter Einfluss von Ostseeslawen gebaut wurde.

6 z.B. Tychowo (Sławno), wo man an einer und derselben Stelle ein altes Hünengrab, einen flachen Friedhof und Spuren von menschlicher Tätigkeit aus dem Mittelalter entdeckte (Lachowicz 1974: 329).

7 In den Wäldern und auf den Feldern.

8 Ethnographische Untersuchungen belegen die Existenz von zahlreichen Gestalten dieser Art in der Volksüberlieferung (Baranowski 1981: 157).

${ }^{9}$ Die Kaschuben kennen den Brauch, Stoffteile auf Zweigen, besonders auf Eichenzweigen, aufzuhängen, um Krankheiten zu vertreiben (Treder 1989: 25).

\section{QUELLEN}

Ebbonis 1872 = Ebbonis vita Ottonis episcopi Bambergensis. Bielowski, August (hrsg.). Pomniki dziejowe Polski = Monumenta Poloniae Historica II. Lwów: Nakł. Własnym, S. 32-70.

Helmolda 1974 = Helmoldus Bosoviensis (Verfasser) \& Matuszewski, Józef (hrsg.). Helmolda Kronika Slowian = Chronica Slavorum. Warszawa: Państw. Wyd. nauk.

Herbordi 1872 = Herbordi vita Ottonis episcopi Bambergensis, Bielowski, August (hrsg.). Pomniki dziejowe Polski = Monumenta Poloniae Historica, II, Lwów, Nakł. Wlasnym, S. 71-127.

Monachi Prieflingensis 1872 = Monachi Prieflingensis vita Ottonis episcopi Bambergensis. Bielowski, August (hrsg.). Pomniki dziejowe Polski = Monumenta Poloniae Historica II. Lwów: Nakł. Własnym, S. 128-144.

Preussische Chronik 1876 = Grunau, Simon (Verfasser) \& Perlbach, Max (hrsg.). Die preussischen Geschichstschreiber des XVI. und XVII. Jahrhunderts $1=$ Simon Grunau's Preussische Chronik 1. Leipzig: Duncker \& Humblot.

Thietmar 2002 = Thietmar von Merseburg (Verfasser) \& Jedlicki, Marian Zygmunt (hrsg.). Kronika Thietmara. Kraków: Universitas.

\section{LITERATUR}

Abramowicz, Andrzej 1987. Dzieje zainteresowań starożytniczych w Polsce II: Czasy stanisławowskie $i$ ich poklosie. Wrocław \& Warszawa \& Kraków \& Gdańsk \& Łódź: Zakład Narodowy Imienia Ossolińskich Wydawnictwo Polskiej Akademii Nauk.

Afeltowicz, Beata 2004. Nazwy miejscowe od nazw drzew leśnych na Pomorzu Zachodnim. Łysiak, Wojciech (hrsg.). III Ogólnopolska Konferencja pt. "Las w 
kulturze polskiej": Materialy z konferencji: Orzechowo kolo Ustki 16-18 października 2003. Poznań: Wydawnictwo Eco, S. 67-73.

Baranowski, Bohdan 1981. W kręgu upiorów i wilkolaków. Łódź: Wydawn. Łódzkie.

Bertemes, François \& Biehl, Peter F. 2001. The Archaeology of Cult and Religion: An Introduction. Biehl, Peter F. \& Bartemes, François \& Meller, Harald (hrsg.). The Archaeology of Cult and Religion. Archaeolingua 13. Budapest: Archaeolingua Alapítvány, S. 11-24.

Białuński, Grzegorz 1993. Bogini Kurko - główny kult Galindii. Komunikaty MazurskoWarmińskie (KMW) 1, S. 3-10.

Białuński, Grzegorz 2002. Las w wierzeniach Prusów. Łysiak, Wojciech (hrsg.). II Ogólnopolska Konferencja "Las w kulturze polskiej”: Materialy z konferencji: Gołuchów 14-16 września 2001. Poznań: Wydawnictwo Eco, S. 575-583.

Biermann, Felix 2006. Usedom - An Early and High Medieval Political and Economic Centre in the Oder Estuary. Møller Hansen, Keld \& Buck Pedersen, Kristoffer (hrsg.).Across the Western Baltic: Proceedings from an Archaeological Conference in Vordingborg. Sydsjællands Museums Publikationer 1. Vordingborg: Sydsjællands Museum, S. 293-303.

Błaszczyk, D. 2000. Obraz i funkcja lasu w życiu społeczeństwa wczesnośredniowiecznej Polski (X-XIII wiek). Lysiak, Wojciech (hrsg.). I Ogólnopolska Konferencja "Las w kulturze polskiej”: Materialy z konferencji. Goluchów 13-15 października 1999. Poznań: Wydawnictwo Eco, S. 49-59.

Bonowska, Magdalena 1999. Kult zmarlych na Pomorzu Zachodnim na przełomie XIX i XX wieku. Łysiak, Wojciech (hrsg.). V Konferencja Stowińsko-Kaszubska: Materialy z konferencji Rowy, 4-5 września 1998. Poznań: Wydawnictwo Eco, S. 6781.

Bonowska, Magdalena 2002. Poza grobem: Gałąki i kamienie pamięci. Kolbuszewski, Jacek (hrsg.). Problemy wspólczesnej tanatologii: Medycyna - antropologia kultury - humanistyka 6: Materialy VI Krajowej Konferencji TANATOS 2002, zorganizowanej przez Wroclawskie Towarzystwo Naukowe $w$ Karpaczu $w$ dniach 7-9 listopada 2002 r. Wrocław: Wrocławskie Towarzystwo Naukowe, S. 601-607.

Buko, Andrzej 2004. Czy pogańskie cmentarze słowiańskie były miejscami religijnego kultu? Kobyliński, Zbigniew (hrsg.). Hereditatem cognoscere: Studia i szkice dedykowane Profesor Marii Miśkiewiczowej. Warszawa: Warsaw University, S. 67-78.

Bylina, Stanisław 1996. Problemy słowiańskiego świata zmarlych: Kategorie czasu i przestrzeni. Światowit 40, S. 9-25.

Bystroń, Jan Stanisław 1980. Przeżytki wiary w magiczną moc słowa. Bystroń, Jan Stanisław (Verfasser) \& Stomma, Ludwik (hrsg.). Tematy, które mi odradzano: Pisma etnograficzne rozproszone, Warszawa: Państwowy Instytut Wydawniczy, S. 204-218.

Cetwiński, Marek \& Derwich, Marek 1989. Herby, legendy, dawne mity. Warszawa: Krajowa Agencja Wydawnicza.

Dudley, John 1846. Naology: Or, a Treatise on the Origin, Progress and Symbolical Import of the Sacred Structures of the Most Eminent Nations and Ages of the World. London: F. and J. Rivington.

Duma, Jerzy 2002. Las, gaj, drzewo, dąb w świadomości dawnych Słowian. Łysiak, Wojciech (hrsg.). II Ogólnopolska Konferencja “Las w kulturze polskiej”: Materialy 
z konferencji: Goluchów 14-16 września 2001. Poznań: Wydawnictwo Eco, S. 2733 .

Eliade, Mircea 1988. Metodologiczne uwagi o badaniu symboliki religijnej. Polska Sztuka Ludowa 62: 3, S. 161-166.

Eliade, Mircea 2000. Traktat o historii religii. Warszawa: Wydawnictwo KR.

Frazer, George James 1969. Zlota Gałąź. Warszawa: Państwowy Instytut Wydawniczy. Grad, J. 2000. Las jako przestrzeń kulturowa. Łysiak, Wojciech (hrsg.). I Ogólnopolska Konferencja "Las w kulturze polskiej”: Materialy z konferencji: Gołuchów 13-15 października 1999. Poznań: Wydawnictwo Eco, S. 17-30.

Haavio, Martti 1979. Mitologia fińska. Warszawa: Państwowy Instytut Wydawniczy.

Holtorf, Cornelius J. 1997. Christian Landscape of Pagan Monuments: A Radical Constructivist Perspective. Nash, George (hrsg.). Semiotics of Landscape: Archaeology of Mind. BAR: International Series 661. Oxford: Archaeopress, S. 8088.

Jonuks, Tõnno 2007. Holy Groves in Estonian Religion. Estonian Journal of Archaeology 11: 1, S. 3-35.

Kaczmarek, Elżbieta 2006. Las i jego mieszkańcy w kulturze ludowej. Łysiak, Wojciech (hrsg.). IV Ogólnopolska Konferencja pt. "Las w kulturze polskiej”: Materialy $z$ konferencji: Mierki kolo Olsztynka, 19-21 maja 2005. Poznań: Wydawnictwo Eco, S. 509-515.

Kajkowski, Kamil 2005. Wczesnośredniowieczne święte gaje i drzewa pogańskich Slowian na terenie Polski (ze szczególnym uwzględnieniem Pomorza). Nasze Pomorze: Rocznik Muzeum Zachodnio-Kaszubskiego w Bytowie 7, S. 125-137.

Knoop, Otto 1895. Neue Volkssagen aus Pommern. Blätter für Pommersche Volkskunde 6: 3, S. 35.

Kowalik, Artur 2004. Kosmologia dawnych Slowian: Prolegomena do teologii politycznej dawnych Slowian. Kraków: Zakład Wydawniczy Nomos.

Kuczkowski, Andrzej 2004. Stan i potrzeby badań nad Górą Chełmską (Krzyżanką) koło Koszalina. Koszalińskie Zeszyty Muzealne 24, S. 69-93.

Kuczkowski, Andrzej 2005. Analiza wczesnośredniowiecznej ceramiki naczyniowej z Góry Chełmskiej (stan. 1) koło Koszalina. Koszalińskie Zeszyty Muzealne 25, S. 21-45.

Kuczkowski, Andrzej 2007. Słowiańskie "święte" góry na terenie ziem polskich we wczesnym średniowieczu - próba zarysowania problematyki. Slavia Antiqua 48, S. 97-123.

Kuczkowski, Andrzej zu druckt a. Magiczno-symboliczna organizacja przestrzeni masywu Góry Chelmskiej kolo Koszalina w średniowieczu i czasach nowożytnych.

Kuczkowski, Andrzej zu druckt b. Podania ludowe o Górze Chełmskiej (Krzyżance) koło Koszalina, Stargardia. Rocznik Muzeum w Stargardzie.

Kuczkowski, Andrzej zu druckt c. Tradycja kontynuacji ośrodków kultu pogańskiego na Pomorzu, Stargardia. Rocznik Muzeum w Stargardzie.

Lachowicz, Franciszek J. 1974. Badania archeologiczne w województwie koszalińskim w latach 1945-1973. Lachowicz, Franciszek J. (hrsg.). Studia Archaeologica Pomeranica: Profesorowi doktorowi Janowi Żakowi w 25-lecie pracy naukowej. Seria Wydawnictw Monograficznych 2. Koszalin: Muzeum Archeologiczno-Historyczne w Koszalinie, S. 279-365. 
Leeuv, Gerardus van der 1978. Fenomenologia religii. Warszawa: Książka i Wiedza.

Lutovský, Michal 1996. Between Sutton Hoo and Chernaya Mogila: Barrows in Eastern and Western Early Medieval Europe. Antiquity 70, S. 671-676.

Łapo, Jerzy Marek 2007.Co wynika z leżenia pod lipa, albo o tym czy lud mazurski zachował pamięć o świętych gajach pruskich? Łysiak, Wojciech (hrsg.). V Ogólnopolska Konferencja pt.: "Las w kulturze polskiej": Materialy z konferencji, Cisna, 19-21 maja 2006., Poznań: Wydawnictwo Eco, S. 487-491.

Łuka, Leon Jan 1973. Wierzenia pogańskie na Pomorzu wschodnim w starożytności i we wczesnym średniowieczu. Zeszyty popularnonaukowe Muzeum Archeologicznego w Gdańsku 2. Wrocław \& Warszawa \& Kraków \& Gdańsk: Zakład Narodowy im. Ossolińskich.

Maciszewski, Rafał 2004. Mity skandynawskie. Warszawa: DiG.

Marczewska, Marzena 2001. Aspekty wierzeniowe w rekonstrukcji językowego obrazu drzew. Język a kultura 16, S. 83-98.

Mielczarski, Stanisław 1992. Działalność misyjna Wojciecha i Ottona. Studia Gdańskie 9, S. 61-74.

Mierzyński, Antoni 1896. Źródla do mytologii litewskiej, cz. 2: Wiek XIVi XV. Monumenta, Mythologiae Lituanicae 2. Warszawa: Dr. Kowalewskiego.

Moszyński, Kazimierz 1932. Kultura ludowa Slowian 2: Kultura duchowa. Kraków Polska Akademja Umiejętności.

Moszyński, Leszka 1998. Dlaczego naukowe opisy prasłowiańskich wierzeń są tak różnorodne. Studia Mythologica Slavica 1, S. 35-44.

Moździoch, Slawomir 2000 Archeologiczne ślady kultu pogańskiego na Śląsku wczesnośredniowiecznym. Moździoch, Sławomir (hrsg.). Czlowiek, sacrum, środowisko: Miejsca kultu we wczesnym średniowieczu. Spotkania Bytomskie 4. Wroclaw: Instytut Archeologii i Etnologii, Polska Akademia Nauk, Oddz. we Wrocławiu, S. 155-193.

Niewęgłowski, A. 1993. Leszczyna i orzechy laskowe jako materialne korelaty religii w Polsce przedchrześcijańskiej. Kwapiński, Marian \& Paner, Henryk (hrsg.). Wierzenia przedchrześcijańskie na ziemiach polskich. Gdańsk: Muzeum Archeologiczne w Gdańsku, S. 47-55.

Noort, Robert van der 1993. The Context of Early Medieval Barrows in Western Europe. Antiquity 67, S. 66-73.

Olszewski, Mikolaj 2002. Świat zabobonów w średniowieczu: Studium kazania "O zabobonach" Stanislawa ze Skarbimierza. Warszawa: Semper.

Osięgłowski, Janisław 1971. Wyspa słowiańskich bogów. Warszawa: Książka i Wiedza.

Pastoureau, Michel 2006. Średniowieczna gra symboli. Warszawa: Oficyna Naukowa.

Powierski, Jan \& Śliwiński, Błażej \& Bruski, Klemens 1993. Studia z dziejów Pomorza $w$ XII wieku. Slupsk: Polskie Towarzystwo Historyczne.

Ricouer, Paul 2007. Pamięć, historia, zapomnienie. Kraków: Universitas.

Rogge, Heinrich 1927. Der Sagenkranz von Neustettin: Ein Volks- und Heimatbuch. Neustettin: Norddeutsche Presse.

Rosik, Stanisław 2000. Awans słońca w mitologii przedchrześcijańskiej Słowian na tle przemian społeczno - politycznych. Moździoch, Sławomir (hrsg.) Czlowiek sacrum - środowisko. Miejsca kultu we wczesnym średniowieczu, Spotkania 
Bytomskie, IV, Wroclaw: Instytut Archeologii i Etnologii Polskiej Akademii Nauk, Oddział we Wrocławiu.

Rzepnikowska, Iwona 2002. Las w czasoprzestrzeni ludowej bajki magicznej. Łysiak, Wojciech (hrsg.). II Ogólnopolska Konferencja “Las w kulturze polskiej”; Materialy z konferencji: Goluchów 14-16 września 2001. Poznań: Wydawnictwo Eco, S. 607-613.

Samsonowicz, Henryk 1997. Mit bohatera. Samsonowicz, Henryk O "historii prawdziwej”: Mity: Legendy i podania jako źródlo historyczne. Gdańsk: Novus Orbis, S. 157-171.

Schuldt, Ewald 1976. Der altslawische Tempel von Gross Raden. Bildkataloge des Museums für Ur- und Frühgeschichte Schwerin 19. Schwerin: Museum für Ur- und Frühgeschichte Schwerin.

Sedov, Valentin V. 1981. Pagan Sanctuaries and Idols of the Eastern Slavs. Slavica Gandensia 7-8, S. 69-85.

Semple, Sarah 1998. A Fear of the Past: The Place of the Prehistoric Burial Mounds in the Ideology of Middle and Later Anglo-Saxon England. World Archaeology 30: 1, S. 109-126.

Skiba, Robert 1999. Górka Klasztorna - przejawy kultu religijnego: Tradycja i współczesność. Rocznik Nadnotecki 30, S. 93-104.

Słupecki, Leszek P. 1995. Pielgrzymka Hermana, towarzysza św. Ottona do posagu Trzygłowa. Komunikat. Manikowska, Halina \& Zaremska, Hanna (hrsg.). Peregrinationes: Pielgrzymki w kulturze dawnej Europy. Colloquia Mediaevalia Varsoviensia 2. Warszawa: Instytut Historii Polskiej Akad. Nauk, S. 51-54.

Słupecki, Leszek P. 2000. Sanktuaria w świecie natury u Słowian i Germanów. Święte gaje i ich bogowie Moździoch, Slawomir (hrsg.). Czlowiek, sacrum, środowisko: Miejsca kultu we wczesnym średniowieczu. Spotkania Bytomskie 4. Wroclaw: Instytut Archeologii i Etnologii, Polska Akademia Nauk, Oddz. we Wrocławiu, S. 39-47.

Słupecki, Leszek P. 2006. Miejsca kultu pogańskiego w Polsce na tle badań nad wierzeniami Słowian. Chudziak, Wojciech \& Moździoch, Sławomir (hrsg.). Stan $i$ potrzeby badań nad wczesnym średniowieczem w Polsce - 15 lat później. Toruń \& Wrocław \& Warszawa: Wydawnictwo Uniwersytetu Mikołaja Kopernika, S. 6382.

Stępiński, Włodzimierz 2000. Misja biskupa Ottona z Bambergu w Szczecinie i na Pomorzu Zachodnim. Bartnik, Paweł \& Kozłowski, Kazimierz (hrsg.). Lata transformacji ustrojowej na Pomorzu Zachodnim: 1989-2000. Regiony w dziejach Polski: Pomorze Zachodnie w tysiącleciu 9. Szczecin: Dokument, S. 69-73.

Treder, Jerzy 1989. Frazeologia kaszubska a wierzenia i zwyczaje (na tle porównawczym). Wejherowo: Muzeum Piśmiennictwa i Muzyki Kaszubsko-Pomorskiej w Wejherowie.

Tyszkiewicz, Józef 1972. Święte drzewa. Z Otchłani Wieków 38: 2, S. 136-140.

Tyszkiewicz, Józef 2003. Dąb w kulturze Słowian wczesnośredniowiecznych. Tyszkiewicz, Józef. Geografia historyczna Polski w średniowieczu: Zbiór studiów, Warszawa: DiG, S. 151-171.

Urbańczyk, Stanisław 1947. Religia pogańskich Slowian. Biblioteka studium słowiańskiego: Universytetu Jagiellońskiego B: 5. Kraków. 
Wrońska, Jolanta 1986. Archeolodzy warszawscy na początku XX wieku. Wrocław: Zakład Narodowy Imienia Ossolińskich.

Zahajkiewicz, Marek Tomasz 2000. Metody chrystianizacji na ziemiach polskich na przykładzie misji pomorskiej św. Ottona z Bambergu. Roczniki Teologiczne 47: 4, S. 37-46. 